\title{
"Negative factors of beliefs toward advertising on Facebook and their effect on attitudes"
}

\begin{tabular}{|c|c|}
\hline AUTHORS & Hilda Bongazana Dondolo iD http://orcid.org/0000-0002-5978-1708 \\
\hline ARTICLE INFO & $\begin{array}{l}\text { Hilda Bongazana Dondolo (2017). Negative factors of beliefs toward advertising } \\
\text { on Facebook and their effect on attitudes. Problems and Perspectives in } \\
\text { Management, 15(2-2), 404-410. doi:10.21511/ppm.15(2-2).2017.09 }\end{array}$ \\
\hline DOI & http://dx.doi.org/10.21511/ppm.15(2-2).2017.09 \\
\hline RELEASED ON & Friday, 01 September 2017 \\
\hline RECEIVED ON & Friday, 16 December 2016 \\
\hline \multirow[t]{2}{*}{ ACCEPTED ON } & Wednesday, 26 April 2017 \\
\hline & $(c))$ EY-NC \\
\hline LICENSE & $\begin{array}{l}\text { This work is licensed under a Creative Commons Attribution-NonCommercial } 4.0 \\
\text { International License }\end{array}$ \\
\hline JOURNAL & "Problems and Perspectives in Management" \\
\hline ISSN PRINT & $1727-7051$ \\
\hline ISSN ONLINE & $1810-5467$ \\
\hline PUBLISHER & LLC "Consulting Publishing Company "Business Perspectives" \\
\hline FOUNDER & LLC "Consulting Publishing Company "Business Perspectives" \\
\hline & ニシニ \\
\hline NUMBER OF REFERENCES & NUMBER OF FIGURES \\
\hline 38 & 0 \\
\hline
\end{tabular}

(c) The author(s) 2023. This publication is an open access article. 


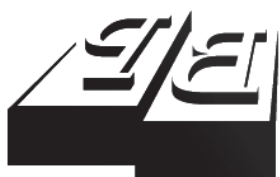

BUSINESS PERSPECTIVES

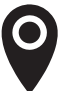

LLC "CPC "Business Perspectives" Hryhorii Skovoroda lane, 10, Sumy, 40022, Ukraine

www.businessperspectives.org

Received on: $16^{\text {th }}$ of December, 2016 Accepted on: $26^{\text {th }}$ of April, 2017

๑) Hilda Bongazana Dondolo, 2017

Hilda Bongazana Dondolo, Tshwane University of Technology, South Africa.

\section{NEGATIVE FACTORS OF BELIEFS TOWARD ADVERTISING ON FACEBOOK AND THEIR EFFECT ON ATTITUDES}

\begin{abstract}
Previous research has studied the effects of materialism, value corruption and falsity, which were identified by Pollay and Mittal (1993) as negatively impacting the beliefs about advertising. Few, if any, assessed negative beliefs about Facebook advertising. This paper assesses such beliefs and how these beliefs influence attitudes toward advertising on Facebook. To meet the objectives of the study, 269 undergraduate students completed the questionnaire. Regression analysis was used to examine a relationship between the beliefs about Facebook advertising and attitudes. In line with hypotheses developed for this study, results showed that respondents of this study view Facebook advertising as promoting materialism, corrupting society's values and misleading and thus negatively impacting their attitudes toward Facebook advertising. This paper concludes with the discussion of results and offers the limitation of the study. The study also provides directions for future research.
\end{abstract}

\section{Keywords \\ advertising, Facebook, beliefs, materialism, value corruption}

\section{JEL Classification M37}

\section{INTRODUCTION}

Advertising is described as paid-for messages channelled through various media outlets and these messages are used to modify consumer perceptions (Belch \& Belch, 2004). The general aim of advertising is to persuade people to buy products and services (Obermiller \& Spangenberg, 1998). However, there are concerns that advertising might negatively influence an individual's belief system (Bauer \& Greyser, 1968). One way to address and perhaps reduce concerns about advertising is to properly select the most appropriate media vehicle to carry the advertising messages.

An increasingly popular media used by advertisers is Facebook. With 1.71 billion monthly users (Zephoria, 2016), Facebook is not only a social networking medium, but also is a pervasive and powerful medium that advertisers use to reach billions of users. In the US alone, it is estimated that Facebook advertising revenues grew by $\$ 22.37$ billion by the end of 2016 (eMarketer, 2016). Developing countries like South Africa, with at least 14 million active users (WorldWideWorx, 2017), are also contributing to Facebook global ad revenues (AFKInsider, 2016).

Despite the significant growth prospect Facebook is offering in South Africa, research to date has not fully explored users' beliefs with special reference to negative beliefs about Facebook advertising. Therefore, 
the purpose of this paper is to assess negative beliefs and how these beliefs are linked to attitudes towards advertising on Facebook. The negative beliefs were chosen, because such beliefs are known to immensely affect consumers' advertising attitudes (Buijzen \& Valkenburg, 2003) and purchase intentions (Yang, 2004).

\section{BELIEFS ABOUT ADVERTISING}

Beliefs refer to "specific statements describing the attributes or consequences of objects" (Wang \& Sun, 2010, p. 334). Opinions, judgements and values that individuals hold about objects all represent beliefs (Boekaerts, 2002). Thus, beliefs entail information a person has about other people or objects (Andrews, 1989).

One of the phenomena known to influence an individual's belief system is advertising. Converging evidence suggests that consumers generally possess beliefs about advertising. To fully understand beliefs about advertising in general, two models are examined - the Bauer and Greyser (1968) and the Pollay and Mittal (1993) models. Fundamentally, both models deal with beliefs about advertising differing to a certain extent in their categorization of these beliefs. For instance, Bauer and Greyser (1968) categorized beliefs into economic and social levels. Economic dimension focuses on economic benefits of advertising (e.g., advertising is essential, advertising helps raise the living standards advertising results in better products for the public and advertising results in lower prices). The social dimension of the belief model focuses on how advertising promotes materialism and value corruption. The Pollay and Mittal (1993) model categorizes consumers' beliefs about advertising into personal uses and societal effects. The personal use category consists of factors like product information, social role and image and hedonic/pleasure. The societal effects category consists of factors like value corruption, falsity/no sense, good for the economy and materialism. Based on the foregoing discussions, it can be concluded that both models view societal factors as eliciting negative evaluations about advertising, leading to an observation that, globally, advertising is seen as a typical phenomenon that may induce negative beliefs that may have an influence on society (Buijzen \& Valkenburg, 2003).
From previous studies, negative beliefs related to advertising range from perceptions of advertising as breeding vulgarity, fostering envy, greed, conformity, anxieties, competitiveness and creation of dissatisfaction (Pollay, 1986; Ciochetto, 2011). Other authors (Galbraith, 1975; Ciochetto, 2011) maintain that advertising is self-serving making people buy products they cannot afford just to show off; promoting products that are bad for the society; raising the prices of products without adding value; promoting harmful behavior; and depicting too much sex (Pollay, 1986; Ciochetto, 2011).

Based on the foregoing arguments, Pollay (1986) vehemently concluded that advertising is "acting only for its own ends" (p. 25), proposing that advertising's style of persuasion is inherently irrational, seeking acceptance through identification, association or images. It is such a negative view about advertising which shaped Pollay and Mittal's (1993) concluding remarks that advertising is one of the sinful forces of modern society and promotes cultural sins by fostering materialism, corrupting values and promoting falsity. Drawing from the Pollay and Mittal (1993) model of beliefs and attitudes toward advertising and building from other significant literature on beliefs and attitudes toward advertising in general or in a particular medium, this paper seeks to examine factors considered to negatively influence beliefs and attitudes towards Facebook advertising.

\section{FACTORS PERTAINING TO NEGATIVE BELIEFS ABOUT ADVERTISING}

\subsection{Materialism}

Advertising is blamed for exacerbating many ills and encouraging people to buy things they do not need (Coulter, Zaltman, \& Coulter, 2001) while promoting unhealthy destructive values like mate- 
rialism (Wang \& Sun, 2010). Richins and Dawson (1992) define materialism as "set of centrally held beliefs about the importance of possessions in one's life" (p. 308). As far as Lasch (1978) is concerned, advertising influences people to find the meaning of life in products by propagating an idea that possessions are more important than one's wellbeing (Pollay, 1986; Wulfemeyer \& Mueller, 1992). Based on the foregoing discussion, Chia (2010) advances the notion that advertising may be a source of support for materialistic values and may even persuade people that material possessions are life goals. Previous research found a relationship between materialism and attitudes toward advertising. In their study, Wolin, Korgaonkar, and Lund (2002) found that materialism significantly influenced attitudes toward advertising. Thus, the following hypothesis is formulated:

\section{H1: Beliefs that Facebook advertising promotes materialism negatively influences attitudes toward advertising.}

\subsection{Value corruption}

Advertising, good as it may be in persuading consumers and the fact that it is unquestionably responsible for equipping consumers to make choices and helps raise the living standards is weakened by many ills. According to Andrews (1989), advertising manipulates values against the individual's own will by promoting "sinful" values (Pollay, 1986). Thus, certain media used to carry advertising messages are known to be instrumental in promoting moral value decay, as they carry content that reflects sexual themes and images (Reichert, 2002), which may impact negatively the effectiveness of advertising (Singh \& Sandhu, 2011). There has been a link between beliefs about value corruption and attitudes toward advertising. Pollay and Mittal (1993) observed that consumers' beliefs about value corruption are related to their attitudes towards advertising. As a result, certain consumers display more negative attitudes when they believe advertising manipulates people's values (Wang, Sun, Lei, \& Toncar, 2009). Based on the above review, the following hypothesis is formulated:

H2: Beliefs that Facebook advertising promotes value corruption will significantly influence attitude toward it.

\subsection{Falsity}

Advertising is known for its key role in encouraging people to buy products that help them achieve idealized images (Coulter, Zaltman, \& Coulter, 2001) and thereby misrepresenting the attributes of products being sold (Wolin, Korgaonkar, \& Lund, 2002). Therefore, Pollay and Mittal (1993) concluded that advertising is purposefully misleading and exacerbating the falsity factor and thereby influencing consumers' attitudes. Hence, the following hypothesis is formulated:

H3: Beliefs that Facebook advertising is misleading will have an influence on attitude toward advertising.

\subsection{Attitudes toward advertising}

According to Lutz (1985), attitude toward advertising in general refers to "a learned predisposition to respond in a consistently favorable or unfavorable manner to advertising in general" (p. 53). Generally, consumers may hold favorable or unfavourable attitudes toward advertising. Studies (Ducoffe, 1996; Tsang, Ho, \& Liang, 2004; Chowdhury, Parvin, Weitenberner, \& Becker, 2010) suggest that individuals with more favorable attitudes toward advertising find advertising trustworthy, informative, entertaining, enjoyable, credible and so forth. Research further indicate that those individuals who have unfavorable attitudes toward advertising may find it irritating, promoting materialistic values, corrupting society's value and deceitful by misrepresenting attributes of certain products (Andrews, 1989; Pollay \& Mittal, 1993; Coulter, Zaltman, \& Coulter, 2001; Wolin, Korgaonkar, \& Lund, 2002; Wang \& Sun, 2010).

\subsection{Sample}

One group whose views matters most to advertisers and who are of interest to researchers is the student sample group. Therefore, the sample of this study was obtained from university students. Although the use of the student sample may limit the generalization of the findings (Wang, Zhang, Zang, \& Ouyang, 2005), Beltramini (1983) maintained that students are 
a useful surrogate of the general population. Also, Durvasula, Mehta, Andrews, and Lysonski (1997) agree with this view when they found no difference between the students' perceptions of advertising and the perceptions of the general consumer. Since most of the students are heavy users of Facebook (Chu \& Kim, 2011), they form the best target group for Facebook advertising. Therefore, Facebook is likely to be an important vehicle through which this population group could be reached by advertisers. Furthermore, previous research (Previte, 1999; Yang, 2000; Brackett \& Carr, 2001; Tsang, Ho, \& Liang, 2004) on beliefs and attitudes toward advertising has made use of a student sample.

A self-administered questionnaire was distributed to 300 students at a higher education institution in the Gauteng province of South Africa. The questionnaire was administered during class and no incentives were given to students. Of the 300 questionnaires distributed, 269 were usable.

\section{RESPONDENTS' DEMOGRAPHIC PROFILE}

From the majority of the respondents, 55 percent were female and 45 percent male. The sample of this study consisted of participants ranging in age from 18 years old (7\%), 19 years old (11\%), 20 years old $(21 \%), 21$ years old $(25 \%), 22$ years old (17\%), 23 years old (8\%), 24 years old (5\%) and over 24 years old (6\%). Of these respondents, 57 percent accessed Facebook daily, 18 percent accessed it a few times a week, four percent once a week, nine percent a few times per month, and 12 percent once a month. Fifty-five percent spend less than an hour on Facebook,
20 percent spend up to two hours per day on Facebook, 11 percent spend two to four hours on Facebook per day, eight percent spend more than eight hours, three percent spend four to six hours, and three percent spend six to eight hours on Facebook per day.

\section{THE QUESTIONNAIRE}

The questionnaire had two major parts, the biographic section and a section that asked the respondents about their belief system. Beliefs toward Facebook advertising were measured on a six-point scale ranging from strongly disagree (1) to strongly agree (6) as end points. The beliefs' scale included the Bauer and Greyser (1968) belief statements measuring value corruption and materialism.

\section{DATA ANALYSIS}

The data for this study were analyzed using Statistical Package for Social Sciences (SPSS) version 24. Two-hundred-and-sixty-nine questionnaires were usable making about 89.6 percent response rate.

\section{RESULTS}

\subsection{Reliability analysis}

Reliability was assessed by Cronbach alpha. The Cronbach alpha values ranged from 0.705 to 0.856 and were above the 0.70 threshold suggesting reliability of the data used in this study. Table 1 shows the Cronbach alpha coefficients for the constructs.

Table 1. Correlations for the belief toward advertising dimensions

\begin{tabular}{l|c|c|c|c|c}
\hline \multicolumn{1}{c}{ Dimension } & Mean & $\begin{array}{c}\text { Cronbach } \\
\text { alpha }\end{array}$ & Attitude & $\begin{array}{c}\text { Value } \\
\text { corruption }\end{array}$ & Falsity \\
\hline Attitude & 3.099 & 0.856 & 1 & Materialism \\
\hline Value corruption & 4.072 & 0.706 & 0.047 & - & - \\
\hline Falsity & 3.418 & 0.724 & $0.468^{* *}$ & $-0.350^{* *}$ & 1 \\
\hline Materialism & 3.353 & 0.705 & $0.289^{* *}$ & $0.352^{* *}$ & $0.476^{* *}$ \\
\hline
\end{tabular}

Note: ${ }^{\star *}$ Correlation is significant at the 0.01 level (2-tailed). 
Table 2. Regression of negative factors of beliefs toward advertising on Facebook

\begin{tabular}{l|l|c|c|c}
\hline \multicolumn{1}{c}{ Dependent variable } & $\begin{array}{c}\text { Independent } \\
\text { variable }\end{array}$ & Beta & t-value & Significance \\
\hline \multirow{3}{*}{ Attitudes } & Materialism & -0.124 & $-1,997$ & 0.047 \\
& Value corruption & -0.154 & -2.723 & 0.007 \\
& Falsity & -0.465 & -7.478 & 0.000 \\
\hline
\end{tabular}

Note: significant at $p<0.05$.

\subsection{Validity analysis}

To assess validity, convergent validity was performed by computing Pearson correlation coefficients between beliefs toward advertising constructs. Table 1 identifies the correlation coefficients of the items.

When the correlations of the beliefs factors were computed, they were significant. Attitude positively correlated with falsity and materialism $(\mathrm{r}=0.468, \mathrm{p}<0.01$, $\mathrm{n}=269 ; \mathrm{r}=0.289, \mathrm{p}<0.01, \mathrm{n}=269$, respectively). Materialism positively and significantly correlated with falsity and value corruption $(\mathrm{r}=0.476, \mathrm{p}<0.01$, $\mathrm{n}=269 ; \mathrm{r}=0.352, \mathrm{p}<0.01, \mathrm{n}=269$, respectively). Value corruption was significantly negatively correlated with falsity $(r=-0.350, p<0.01, n=269)$. The correlations ranged from $r=0.289$ to $r=0.476$ at $p<0.01$ demonstrating adequate convergent validity. To explore the relationship further, regression analysis was conducted.

\subsection{Regression analysis}

To investigate the relationship of dimensions of the beliefs about Facebook advertising to attitudes toward advertising, regression analysis was performed. The dependent variable was attitudes. The results showed a significant relationship between materialism and attitude $(\beta=-0.124 ; p<0.05)$ and falsity and attitude $(\beta=-0.154 ; p<0.05)$. Value corruption was inversely and significantly related to attitude $(\beta=-0.465 ; p<0.05)$. Based on the results of the regression analysis, there was support for all the hypotheses. The results show the value of adjusted $R^{2}=0.238$ indicating that the advertising beliefs dimensions explained $24 \%$ of the variance in attitudes. Table 2 above presents the results of regression analysis for the negative factors of belief toward advertising on Facebook.

\section{DISCUSSION AND CONCLUSION}

The main aim of this study was to assess the negative dimensions of beliefs toward advertising on Facebook and their effect on attitudes. The study used the Pollay and Mittal (1993) advertising beliefs model to provide a theoretical grounding. Based on the review of previous studies on beliefs and attitude toward advertising, three hypotheses were formulated. A regression analysis was applied to test the hypotheses of the study. All the hypotheses were supported. Thus, all the belief factors played an important role in predicting attitudes toward advertising on Facebook. The results revealed a significant relationship between materialism and attitude. One of the argument about advertising is that it exacerbates many ills and encourage people to buy things they do not need (Coulter, Zaltman, \& Coulter, 2001) while promoting unhealthy destructive values like materialism (Wang \& Sun, 2010). Therefore, there is an observation that people who believe advertising promotes materialism will tend to have a negative attitude toward it (Wolin, Korgaonkar, \& Lund, 2002).

The results show that value corruption is negatively related to attitude toward advertising on Facebook. By implication, this indicates that those people who believe Facebook advertising undermines their value system will have a negative attitude toward it, leading to a conclusion that certain advertising tend to compromise values societies cherish (Wang \& Sun, 2010). 
Regarding falsity belief, the findings suggest a relationship between this construct and attitudes toward Facebook advertising. Thus, people tend to view advertising negatively when they believe that it misrepresents the attributes of products being sold (Wolin, Korgaonkar, \& Lund, 2002). These findings are consistent with previous research on beliefs and attitudes toward advertising. Therefore, this study sought to advance our understanding of how negative beliefs about advertising on Facebook influence attitude toward advertising on Facebook, which eventually might impact on purchase behavior (Bush, Smith, \& Martin, 1999).

\section{Limitations and future research}

Although the present study has contributed new knowledge to the existing body of advertising beliefs and attitudes literature, there are a number of limitations with the study. The present study focused only on negative beliefs about Facebook advertising. Therefore, there is a need to expand the focus to include other variables that may have potential effects on advertising beliefs within the Facebook environment. Because Facebook is used not only by students, future research should investigate the same phenomenon using non-student population groups. Beltramini (1983) argues that a student sample may limit the generalization of the findings. However, Durvasula, Mehta, Andrews, and Lysonski (1997) have used a student sample when studying advertising perceptions. They discovered that there was no difference between the students' perceptions of advertising and the perceptions of the general consumer. The research method used in this study has limitations too. To understand the beliefs about Facebook advertising, only quantitative techniques were used. Future research should encourage the use of qualitative approach that aims at fully understanding this phenomenon. According to Goldstein (1986) the major limitation of quantitative techniques is their inability to describe a behavior with precision.

\section{REFERENCES}

1. AFKInsider. (2016). Africa Helped Facebook Break Ad Revenue Records In Q4. Not Everyone Is Celebrating. Retrieved from http:// afkinsider.com/118424/118424/ (accessed on 01.03.2017).

2. Andrews, J. C. (1989). The dimensionality of beliefs toward advertising in general. Journal of Advertising, 18(1), 26-35.

3. Bauer, R. A., \& Greyser, S. A. (1968). Advertising in America: the consumer view. Boston, Mass.: Harvard University. Graduate School of Business Administration. Division of Research.

4. Belch, G. E., \& Belch, M. A. (2004). Advertising and promotion: an integrated marketing communications perspective. 6th ed. Boston, Mass.: Irwin McGrawHill.

5. Beltramini, R. F. (1983). Student surrogates in consumer research. Journal of the Academy of Marketing Science, 11(4), 438-443.

6. Boekaerts, M. (2002). The on-line motivation questionnaire: A self-report instrument to assess students' context sensitivity. Advances in Motivation and Achievement, 12, 77-120.

7. Brackett, L. K., \& Carr, B. N. (2001). Cyberspace advertising vs. other media: Consumer vs. mature student attitudes. Journal of Advertising Research, 41(5), 23-32.

8. Buijzen, M., \& Valkenburg, P. M. (2003). The effects of television advertising on materialism, parent - child conflict, and unhappiness: A review of research. Journal of Applied Developmental Psychology, 24(4), 437-456.

9. Bush, A. J., Smith, R., \& Martin, C. (1999). The influence of consumer socialization variables on attitude toward advertising: A comparison of African-Americans and Caucasians. Journal of Advertising, 28(3), 13-24.

10. Chia, S. C. (2010). How social influence mediates media effects on adolescents' materialism. Communication Research, 37(3), 400-419.
11. Chowdhury, H. K., Parvin, N., Weitenberner, C., \& Becker, M. (2010). Consumer attitude toward mobile advertising in an emerging market: An empirical study. Marketing, 12(2), 206-216.

12. Chu, S., \& Kim, Y. (2011). Determinants of consumer engagement in electronic wordof-mouth (eWOM) in social networking sites. International Journal of Advertising, 30(1), 47-75.

13. Ciochetto, L. (2011). Advertising and value formation: The power of multinational companies. Current Sociology, 59(2), 173-185.

14. Coulter, R. A., Zaltman, G., \& Coulter, K. S. (2001). Interpreting consumer perceptions of advertising: An application of the Zaltman Metaphor Elicitation Technique. Journal of Advertising, 30(4), 1-21.

15. Ducoffe, R. H. (1996). Advertising value and advertising on the web. Journal of Advertising Research, 36(5), 21-21. 
16. Durvasula, S., Mehta, S., Andrews, J., \& Lysonski, S. (1997). Advertising Beliefs and Attitudes: Are Students and General Consumers Different. Journal of Asian Business, 13(1), 74-84.

17. eMarketer. (2016). Facebook Continues to Grow, Steadily Adding New Revenue Streams. Retrieved from https://www.emarketer.com (accessed on 01.11.2016).

18. Galbraith, J. K. (1975). Consumer behavior and the dependence effect. In Mansfield, E. Micro-Economics Selected Readings. Second Edition. USA: WW Norton and Company Inc.

19. Goldstein, R. J. (1986). The limitations of using quantitative data in studying human rights abuses. Human Rights Quarterly, 8(4), 607-627.

20. Lasch, C. (1978). The Culture of Narcissism. New York: W. W. Norton.

21. Lutz, R. J. (1985). Affective and cognitive antecedents of attitude toward the ad: A conceptual framework. In L. F. Alwitt \& A. A. Mitchell (Eds.). Psychological processes and advertising effects: Theory, research and application (p 4543). Hillsdale, NJ: Lawrence Erlbaum Associates, Inc.

22. Obermiller, C., \& Spangenberg, E. R. (1998). Development of a scale to measure consumer skepticism toward advertising. Journal of Consumer Psychology, 7(2), 159-186.

23. Pollay, R. W. (1986). Quality of life in the padded sell: Common criticisms of advertising's cultural character and international public policies. Current Issues and Research in Advertising, 9(1-2), 173-250.
24. Pollay, R. W., \& Mittal, B. (1993). Here's the beef: factors, determinants, and segments in consumer criticism of advertising. The Journal of Marketing, 57(3), 99-114.

25. Previte, J. (1999). Internet advertising: An assessment of consumer attitudes. Prometheus, 17(2), 199-209.

26. Reichert, T. (2002). Sex in advertising research: A review of content, effects, and functions of sexual information in consumer advertising. Annual Review of Sex Research, 13(1), 241-273.

27. Richins, M. L., \& Dawson, S. (1992). A consumer values orientation for materialism and its measurement: Scale development and validation. Journal of Consumer Research, 19(3), 303316

28. Singh, J., \& Sandhu, N. (2011). Building ethical considerations into advertising practices - An Indian study. International Journal of Business and Social Science, 2(18), 291-301.

29. Tsang, M. M., Ho, S. C., \& Liang, T. P. (2004). Consumer attitudes toward mobile advertising: An empirical study. International Journal of Electronic Commerce, 8(3), 65-78.

30. Wang, Y., Sun, S., Lei, W., \& Toncar, M. (2009). Examining beliefs and attitudes toward online advertising among Chinese consumers. Direct Marketing: An International Journal, 3(1), 52-66.

31. Wang, Y., \& Sun, S. (2010). Assessing beliefs, attitudes, and behavioral responses toward online advertising in three countries. International Business Review, 19(4), 333-344.
32. Wang, F., Zhang, H., Zang, H., \& Ouyang, M. (2005). Purchasing pirated software: an initial examination of Chinese consumers. Journal of Consumer Marketing, 22(6), 340-351.

33. Wolin, L. D., Korgaonkar, P., \& Lund, D. (2002). Beliefs, attitudes and behaviour towards Web advertising. International Journal of Advertising, 21(1), 87-113.

34. WorldWideWorx. (2017). South African Social Media Landscape 2017: Executive Summary. Retrieved from http://www. worldwideworx.com/wp-content/uploads/2016/02/SA-SocialMedia-Landscape-2016-Executive-summary.pdf (accessed on 01.03.2017).

35. Wulfemeyer, K. T., \& Mueller, B. (1992). Channel One and commercials in classrooms: Advertising content aimed at students. Journalism \& Mass Communication Quarterly, 69(3), 724-742.

36. Yang, C. C. (2000). Taiwanese students' attitudes towards and beliefs about advertising. Journal of Marketing Communications, 6(3), 171-183.

37. Yang, K. C. (2004). A comparison of attitudes towards Internet advertising among lifestyle segments in Taiwan. Journal of Marketing Communications, 10(3), 195-212.

38. Zephoria. (2016). The Top 20 Valuable Facebook Statistics. Retrieved from https://zephoria. com (accessed on 01.11.2016). Date of access: 1 March 2017. 